Vietnam Journal of Mechanics, VAST, Vol.29, No. 4 (2007), pp. 497-506

\title{
INFLUENCES OF THE COMPRESSIBILITY ON AERODYNAMIC CHARACTERISTICS OF PROFILE UNDER THE TRANSONIC FLOW THEORY
}

\author{
HOANG Thi Bich NGOC \\ Hanoi University of Technology
}

\begin{abstract}
Transonic flows are complex problems. At certain Mach numbers, in gas flows there are local transitions from the subsonic into the supersonic and reciprocally, especially the discontinuity throughout shock waves. Subsonic flows and supersonic flows have very different properties, thus calculation methods are also different - the subsonic equation is elliptic and the supersonic equation is hyperbolic. Using established programs (based on the incompressible theory, the compressible theory and the transonic theory), we studied sub-transonic flow characteristics with variations of the Mach number. Our studies are also carried out with variations of incidence, which impact on the transonic effect. Numerical results show that the local compressibility depends on not only the speed but also the incidence. At, a rather great angle of attack, local supersonic regions can appear with free Mach numbers in the order of 0.3 - the Mach number is normally considered as a speed of incompressible flows. According to these results, we can recognize for which regime the local compressibility of flow is considerable and then it is necessary to consider the problem under the transonic flow theory.
\end{abstract}

\section{INTRODUCTION}

The transonic flow is a mixed flow in which there are locally subsonic and supersonic regions, normally with free stream Mach numbers from 0.7 to 1.2 (Fig. 1). However, experiences and calculations show that transonic flow properties depend also on the body geometry. By using established programs to calculate flows around a profile, it depend on incidences, a supersonic point can occur even Mach number $M \leq 0.3$. The transonic flow is a complex problem, especially when taking into account the viscosity, the problem needs always-experimental results. With advantages of sub-transonic flows $(M<1)$, they are generally used in the civil transportation. In the world, they study transonic flows experimentally and numerically. In our country, studies of transonic and supersonic flows are a beginning. We realized and publicized some computational study works for supersonic flows, and then transonic flows. In this work, we approach numerically the stear'y isentropic potential plan problem and compare the calculated results with published results. Numerical essays show more clear the nature of the transonic flow and influences of fluid compressibility on aerodynamic characteristics under the transonic theory. Since then, we can see optimal and efficacy application domains of the flow type. 

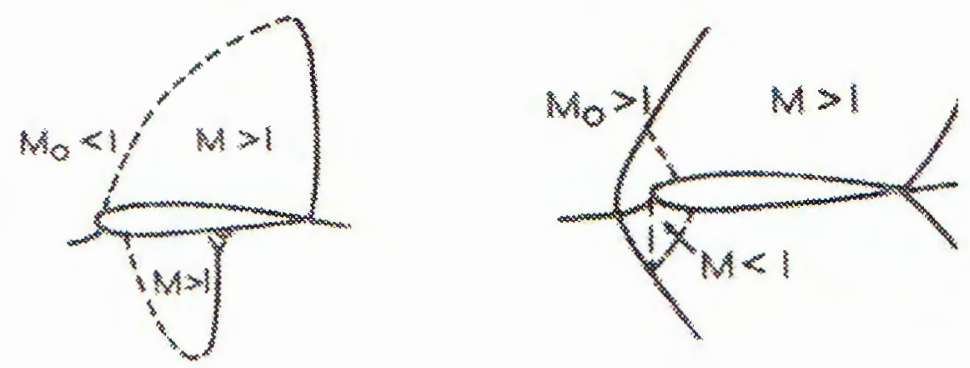

Fig. 1. Transonic flows free Mach number $M_{0}<1$ and $M_{0}>1$

\section{ESTABLISHED PROGRAMS}

We programmed sub-transonic problems by three ways:

1. based on incompressible flow theory;

2. based on compressible flow theory;

3. based on transonic flow theory.

\subsection{Methods for incompressible and compressible flow calculations}

A code for incompressible flows is programmed according to singularity method with linear vortexes [1]. At a point $P$, formulas calculating velocities induced from a vortex distribution of strength $\gamma=\gamma_{0}+\gamma_{1} . x$ can be written as followings ( $\gamma_{0}$ and $\gamma_{1}$ are constant) $[2]:$

$$
\begin{aligned}
u_{p}= & \frac{\gamma_{0}}{2 \pi}\left(\tan ^{-1} \frac{y}{x-x_{2}}-\tan ^{-1} \frac{y}{x-x_{1}}\right) \\
& +\frac{\gamma_{1}}{4 \pi}\left[z \cdot \ln \frac{\left(x-x_{1}\right)^{2}+y^{2}}{\left(x-x_{2}\right)^{2}+y^{2}}+2 x\left(\tan ^{-1} \frac{y}{x-x_{2}}-\tan ^{-1} \frac{y}{x-x_{1}}\right)\right], \\
w_{p}= & \frac{-\gamma_{0}}{4 \pi} \ln \frac{\left(x-x_{1}\right)^{2}+y^{2}}{\left(x-x_{2}\right)^{2}+y^{2}} \\
& -\frac{\gamma_{1}}{2 \pi}\left[\frac{x}{2} \ln \frac{\left(x-x_{1}\right)^{2}+y^{2}}{\left(x-x_{2}\right)^{2}+y 7^{2}}+\left(x_{1}-x_{2}\right)+y\left(\tan ^{-1} \frac{y}{x-x_{2}}-\tan ^{-1} \frac{y}{x-x_{1}}\right)\right] .
\end{aligned}
$$

We divide the profile contour into $\mathrm{N}$ panels with law $x=\frac{c}{2}(1-\cos a)$ to narrow grids near the leading edge and the trailing edge, correspondingly there are $\mathrm{N}$ conditions on the surface and a Joukovski condition. Linear equations are written under following matrix:

$$
\left(\begin{array}{lllll}
a_{11} & a_{12} & \cdot & \cdot & a_{1, N+1} \\
a_{21} & a_{22} & \cdot & \cdot & a_{2, N+1} \\
\cdot & \cdot & \cdot & \cdot & \cdot \\
a_{N, 1} & a_{N, 2} & \cdot & \cdot & a_{N, N+1} \\
1 & 0 & \cdot & 0 & 1
\end{array}\right) \times\left(\begin{array}{l}
\gamma_{1} \\
\gamma_{2} \\
\cdot \\
\gamma_{N} \\
\gamma_{N+1}
\end{array}\right)=\left(\begin{array}{l}
R_{1} \\
R_{2} \\
\cdot \\
R_{N} \\
0
\end{array}\right)
$$

where $a_{i j}=(u, w)_{i j} \cdot n_{i}$, ( $n_{i}$ is the nomal); $R_{i}=-\left(u_{\infty}, w_{\infty}\right) . n_{i}$. Solving the equation system $(2.2)$, we obtain values of singularities $\gamma_{i}[1]$. 
The subsonic compressible flow is calculated by using the linear theory of Prandtl and Glauert which consider the Mach number by taking into account the formula $\sqrt{1-M^{2}}$ [3].

\subsection{Methods for transonic flows}

Codes for transonic flows are programmed according to methods of full potential equation and small disturbance equation.

\subsubsection{Transonic small disturbance method}

\section{a. Equation}

For thin and slender objects with small incidence, disturbances are considered small: $\varphi_{x} / V_{\infty}<<1 ; \varphi_{y} / V_{\infty}<<1$ (where $\varphi$ is disturbance potential, $V_{\infty}$ is free-stream velocity, $\varphi_{x}$ and $\varphi_{y}$ are derivatives). We have small disturbance equation as following [4]:

$$
\left[1-M_{\infty}^{2}-(\gamma+1) M_{\infty}^{2}\left(\frac{\varphi_{x}}{V_{\infty}}\right)\right] \varphi_{x x}+\varphi_{y y}=0 .
$$

Under the derivative form of first order:

$$
\left[\left(1-M_{\infty}^{2}\right) \varphi_{x}-(\gamma+1) \frac{M_{\infty}^{2}}{V_{\infty}} \varphi_{x}^{2}\right]_{x}+\left[\varphi_{y}\right]_{y}=0
$$

with $\gamma$ being the ratio of specific heats at constant pressure and constant volume $C_{P} / C_{V}$.

The equation (2.3) can be witten under form:

$$
A \varphi_{x x}+\varphi_{y y}=0
$$

where

$$
\mathrm{A}=\left[1-M_{\infty}^{2}-(\gamma+1) M_{\infty}^{2}\left(\frac{\varphi_{x}}{V_{\infty}}\right)\right]
$$

It depends on sign of $A(A<0, A=0, A>0)$ that the equation has hyperbolic or parabolic or elliptic types and we can see then the transition from subsonic regime to supersonic regime, and reciprocally.

b. Boundary conditions

Boundary conditions on the surface: $\varphi_{y}=V_{\infty} \frac{d Y}{d x}$ ( $\mathrm{Y}$ is geometry law of the surface). Down the trailing edge at cut line, we have: $\oint_{\text {airfoil }} \vec{V} \cdot d \vec{s}=\oint d \phi=\Delta \phi=\Gamma$ (with $\Gamma$ is circulation). Far field condition for subsonic free stream, using the linear condition $\left(1-M_{\infty}^{2}\right) \varphi_{x x}+\varphi_{y y}=0$, neglecting the term $(\gamma+1) M_{\infty}^{2}\left(\frac{\varphi_{x}}{V_{\infty}}\right)$, we have: $\varphi=\frac{\Gamma}{2 \pi} \arctan \left(\sqrt{1-M_{\infty}^{2} \frac{y}{x}}\right)$.

c. Grid generation

In this case, the profile is modeled as a slit. All of nodes surrounding the profile make up an orthogonal grid, which includes horizontal and vertical lines, with laws:

$$
\Delta x_{i+1}=K_{1} \Delta x_{i} ; \quad \Delta y_{i+1}=K_{2} \Delta y_{i}
$$

Coefficients $K_{1}$ and $K_{2}$ are more than unity. The tangential condition on upper and lower put in mid line:

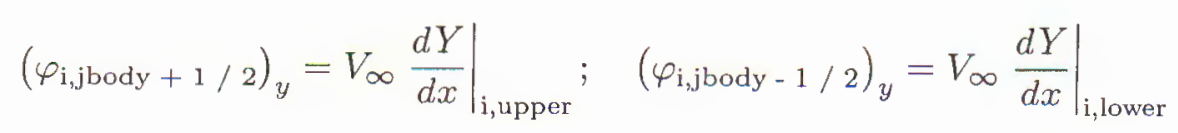




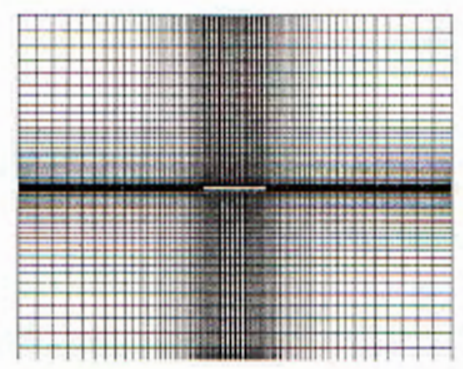

Fig. 2. Grid $(111 \times 66)$

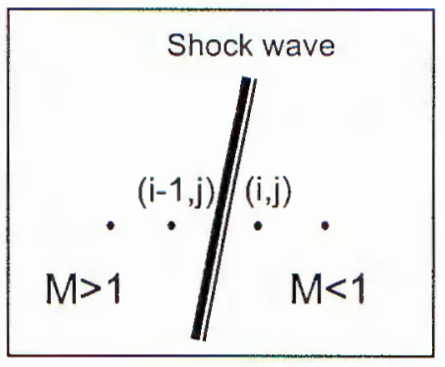

Fig. 3. Shock wave and discontinuity

d. Discretization and solving linear algebric equation

Write small disturbance equation under form:

$$
\frac{\partial P}{\partial x}+\frac{\partial Q}{\partial y}=0
$$

where $P=\left(1-M_{\infty}^{2}\right) \varphi_{x}-(\gamma+1) \frac{M_{\infty}^{2}}{2 V_{\infty}}\left(\varphi_{x}\right)^{2} ; Q=\varphi_{y}$

The sign of A decides that small disturbance equation is in forms of elliptic or hyperbolic. Discretization equation for subsonic and supersonic regions is written as following:

$$
\begin{aligned}
& \frac{P_{i+1 / 2, j}-P_{i-/ 2, j}}{\Delta x_{i}+\Delta x_{i+1}}+\frac{Q_{i, j+1 / 2}-Q_{i, j-1 / 2}}{\Delta y_{j}+\Delta y_{j+1}} \\
& -\left(\delta_{i, j} \frac{P_{i+1 / 2, j}-P_{i-/ 2, j}}{\Delta x_{i}+\Delta x_{i+1}}-\delta_{i-1, j} \frac{P_{i-1 / 2, j}-P_{i-3 / 2, j}}{\Delta x_{i}+\Delta x_{i+1}}\right)=0 .
\end{aligned}
$$

At the discontinuity point of shock wave, this equation make expansion of grid on four nodes: $(i-2, j) ;(i-1, j) ;(i, j) ;(i+1, j) ;(i+2, j)$ (Fig. 3). For supersonic flows, the perturbation propagation is along the movement, $\delta_{i, j}$ and $\delta_{i-1, j}$ are equal to unity. For subsonic flows, $\delta_{i, j}$ and $\delta_{i-1, j}$ are equal to zero.

The equation is solved by iterative method:

$$
\Delta \varphi_{i, j}=\varphi_{i, j}^{n+1}-\varphi_{i, j}^{n}
$$

A good algorithm will give exact solutions when $\Delta \varphi \rightarrow 0$ at all of nodes after some iterations.

Linear equation system of unknowns $\varphi$ can be written:

$$
\begin{aligned}
& B_{i, j} \Delta \varphi_{i-1, j}+C_{i, j} \Delta \varphi_{i-1, j}+D_{i, j} \Delta \varphi_{i, j}+E_{i, j} \Delta \varphi_{i+1, j} \\
& +F_{i, j} \Delta \varphi_{i, j-1}+G_{i, j} \Delta \varphi_{i, j+1}=R_{i, j}^{n} .
\end{aligned}
$$

The right member is residual at iteration level ' $n$ ', which is known.

$$
\begin{aligned}
R_{i, j}^{n}= & \frac{P_{i+1 / 2, j}^{n}-P_{i-1 / 2, j}^{n}}{\Delta x_{i}+\Delta x_{i+1}}+\frac{Q_{i, j+1 / 2}^{n}-Q_{i, j-1 / 2}^{n}}{\Delta y_{j}+\Delta y_{j+1}} \\
& -\left(\delta_{i, j} \frac{p_{i+1 / 2, j}^{n}-p_{i-1 / 2, j}^{n}}{\Delta x_{i}+\Delta x_{i+1}}-\delta_{i-1, j} \frac{p_{i-1 / 2, j}^{n}-p_{i-3 / 2, j}^{n}}{\Delta x_{i}+\Delta x_{i+1}}\right),
\end{aligned}
$$


where $B_{i, j}, C_{i, j}, D_{i, j}, E_{i, j}, F_{i, j}, G_{i, j}$ are:

$$
\begin{aligned}
B_{i, j} & =A_{i-3 / 2} \frac{\delta_{i-1, j}}{\Delta x_{i-1}\left(\Delta x_{i}+\Delta x_{i+1}\right)} ; \\
C_{i, j} & =\left(1-\delta_{i, j}\right) \frac{A_{i-1 / 2, j}}{\Delta x_{i}\left(\Delta x_{i}+\Delta x_{i+1}\right)}-\delta_{i-1, j} \frac{1}{\left(\Delta x_{i}+\Delta x_{i+1}\right)}\left(\frac{A_{i-1 / 2, j}}{\Delta x_{i}}+\frac{A_{i-3 / 2, j}}{\Delta x_{i-1}}\right) ; \\
E_{i, j} & =\left(1-\delta_{i, j}\right) \frac{A_{i+1 / 2, j}}{\Delta x_{i+1}\left(\Delta x_{i}+\Delta x_{i+1}\right)} ; \\
F_{i, j} & =\frac{1}{\Delta y_{j}\left(\Delta y_{j}+\Delta y_{j+1}\right)} ; \\
G_{i, j} & =\frac{1}{\Delta y_{j+1}\left(\Delta y_{j}+\Delta y_{j+1}\right)} ; \\
D_{i, j} & =-\left(1-\delta_{i, j}\right) \frac{\frac{A_{i-1 / 2, j}}{\Delta x_{i}}+\frac{A_{i+1 / 2, j}}{\Delta x_{i+1}}}{\Delta x_{i}+\Delta x_{i+1}}+\delta_{i-1, j} \frac{1}{\left(\Delta x_{i}+\Delta x_{i+1}\right)}\left(\frac{A_{i-1 / 2, j}}{\Delta x_{i}}\right)-\left(F_{i, j}+G_{i, j}\right) .
\end{aligned}
$$

The equation (2.9) is solved by line successive over relaxation scheme with matrix of two diagonals.

2.2.2. Full potential equation method

The full potential equation has following form [4]:

$$
\left(a^{2}-u^{2}\right) \phi_{x x}-2 u v \phi_{x y}+\left(a^{2}-v^{2}\right) \phi_{y y}=0,
$$

where $\phi$ is total potential.

Boundary conditions on profile are:

$$
\phi_{y}=V_{\infty} \frac{d Y}{d x},
$$

where $Y$ is the geometry of profile contour.

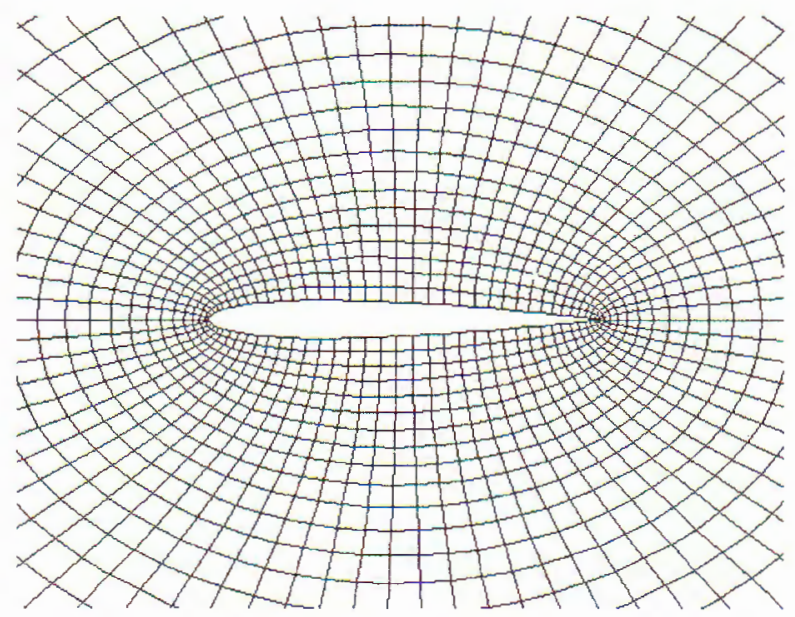

Fig. 4. O grid $(31 \times 81)$ 
Boundary conditions at trailing edge (discontinuity of potential across wake axis) are:

$$
\oint d \phi=\Delta \phi=\Gamma \text {. }
$$

The method and the algorithm of solving this full potential equations (2.12) are presented in [5].

While for the small disturbance potential method profiles are considered very thin, for the full potential method the profile thickness is taken into account, making up grid is much more complex. Here we use Laplace equation to generate an curvilinear surrounding airfoil (elliptic generation) [5], [6].

In Fig. 4 are presented some results of established full potential equation program (FPE program). The case (a) is calculated for Naca 0012, angle of attack $5^{\circ}$ and free Mach number 0.7 with results of Mach field and equi-Mach number lines. Same profile and angle of attack $5^{\circ}$, and different Mach number $M==0.75$ are considered for the case (b) with results of pressure coefficient field and equi-Mach number lines. Physically, shock wave of the case (b) is stronger than one of the case (a) and flow parameters after shock wave position are very different for the two cases.

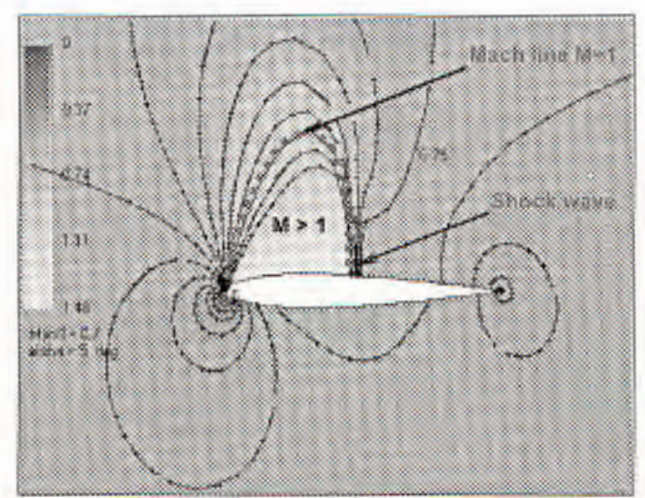

Fig. 5a. Result of present FPE program: Mach field and equi-Mach number lines $\left(M_{\text {inf }}=0.7 ;\right.$ Naca $0012 ;$ Incidence $\left.5^{\circ}\right)$

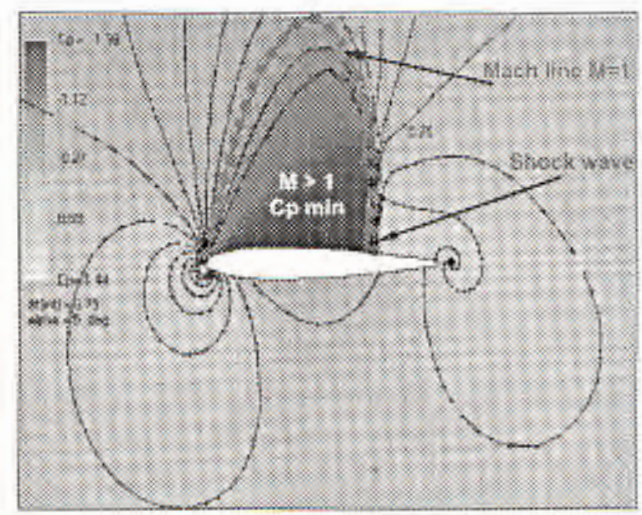

Fig. 5b. Result of present FPE program: Pressure coefficient field and equi-Mach number lines $\left(M_{\text {inf }}=0.75 ; \mathrm{Naca} 0012 ;\right.$ Incidence $\left.5^{\circ}\right)$

\section{COMPARISON OF SOME RESULTS CALCULATED BY ESTABLISHED PROGRAMS}

Fig. 6 shows results of pressure distribution coefficient calculated by two methods: linear vortex method (LVM) for subsonic flows and transonic full potential equation method (FPE). We can see that differences of two methods are very small (for Naca 0012 profile, Mach number $M=0.2$, angle of attack $\alpha=0^{\circ}$ and $\alpha=2^{\circ}$ ).

In Fig. 7, are presented results of pressure distribution coefficient calculated by two transonic methods: small disturbance equation method (SDE) and full potential equation method. Differences are small and seen at the positions of chock wave. We can say that: in these cases when relative thickness is more than $12 \%$, full potential equation method give more exact results. 


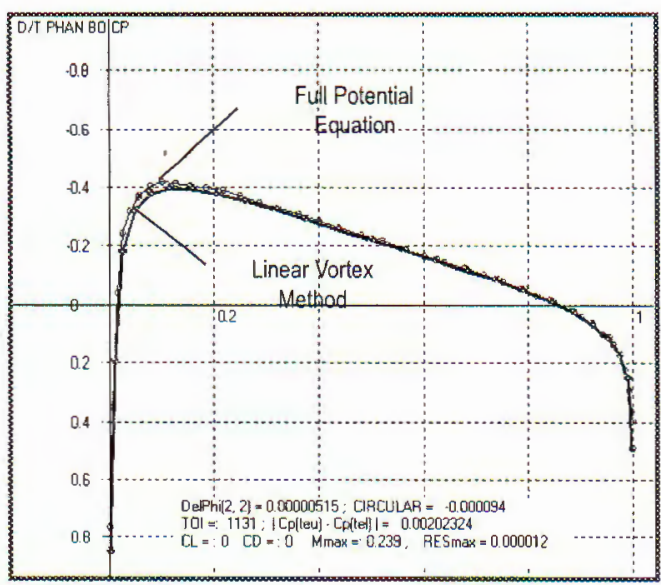

Fig. 6a. Comparison of results calculated by present FPE and LVM programs: $M=0.2$; Naca 0012; Alfa $0^{\circ}$

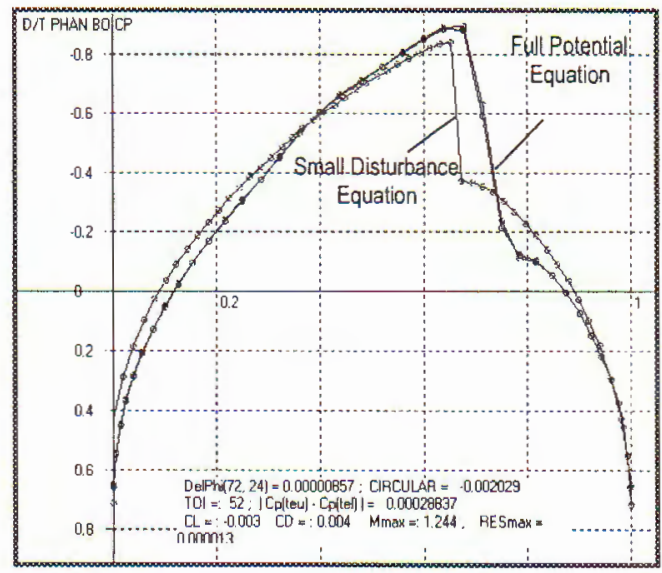

Fig. 7a. Comparison of results calculated by present FPE and SDE programs: $M=0.8$; Arc $12 \%$; Alfa $0^{\circ}$

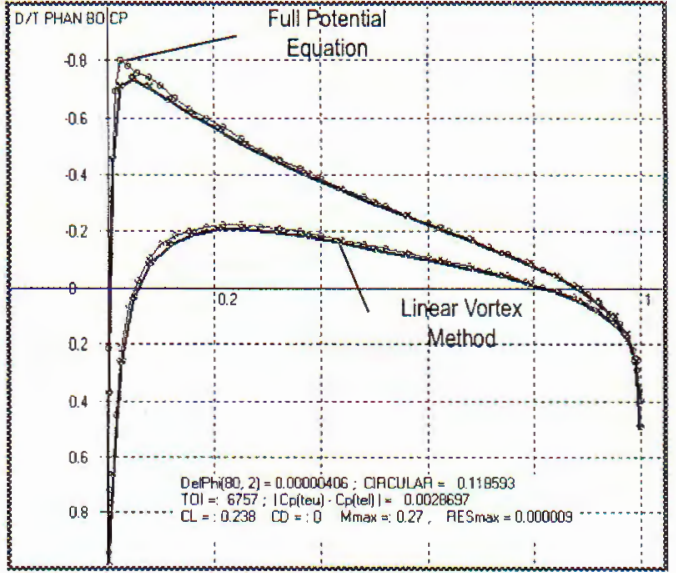

Fig. 6b. Comparison of results calculated by present FPE and LVM program: $M=0.2$; Naca 0012; Alfa $2^{\circ}$

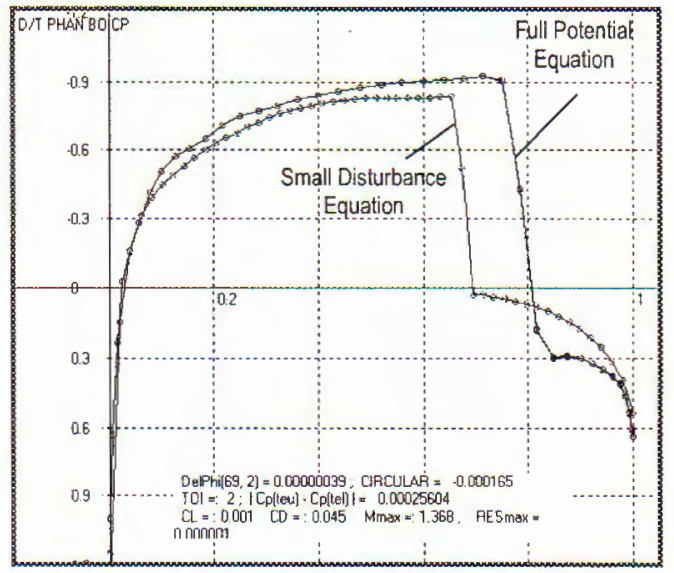

Fig. $\% b$. Comparison of results calculated by present FPE and SDE programs: $M=0.85$; Naca 0012; Alfa $0^{\circ}$

Fig. 8 shows the comparison of results on pressure distribution coefficient calculated by our present FPE program and results of [7] calculated by transonic small disturbance theory equation and Euler equation for case: $M=0.75$, Naca 0012, incidence $2^{\circ}$. Results are similar. Using Fluent software to calculate inviscid transonic flow of case $\mathrm{M}=0.7$; profile Naca $2312 ; 4^{\circ}$ of incidence, and the comparison these results with results calculated by established FPE program is presented in Fig. 9. For this case of transonic flow, shock wave is strong - the two results are not very different, though. 


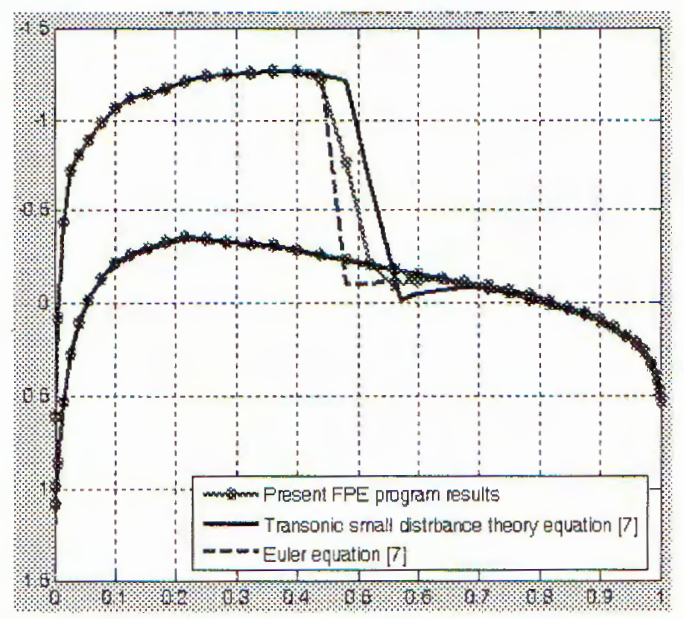

Fig. 8. Comparison of pressure coefficient calculated by present FPE program and results of [7] $M=0.75 ;$ Naca $0012 ;$ Alfa $2^{\circ}$

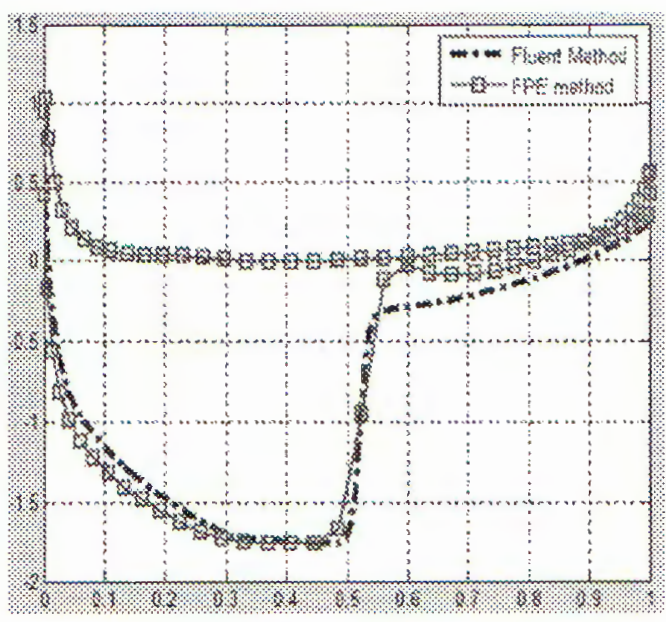

Fig. 9. Comparison of pressure coefficient using Fluent software and present FPE program $M=0.7$; Naca 2312; Alfa $4^{\circ}$

\section{INFLUENCES OF MACH NUMBER AND INCIDENCE}

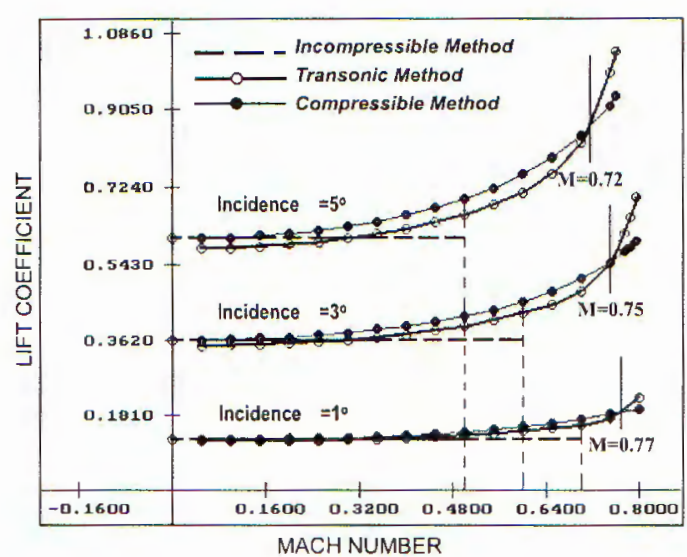

Fig. 10. Dependence of lift coefficient on Mach number with variation of incidence Naca 0012 airfoil

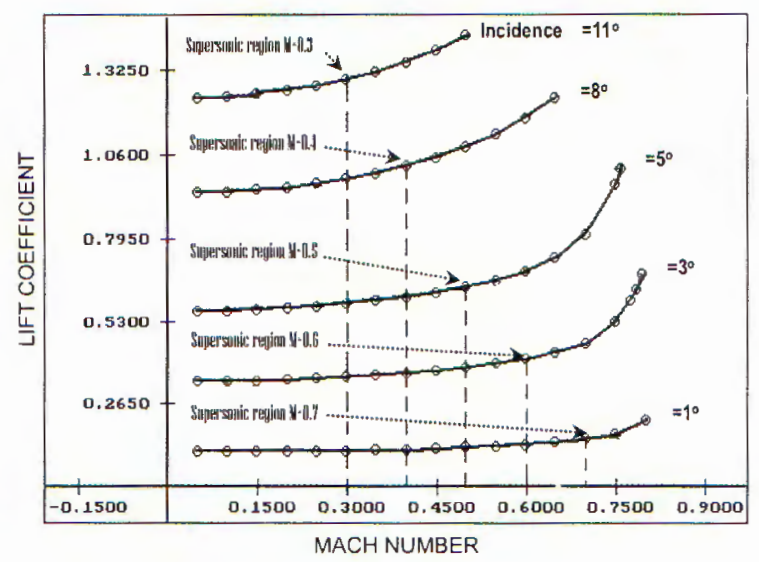

Fig. 11. Lift coefficient calculated by transonic theory

Fig. 10 provides numerical results of lift coefficient depending on Mach number at different angles of attack on a Naca 0012 profile. By comparison of results using three different computational methods (incompressible theory method, compressible theory method and transonic full potential equation method), we can see that differences between results calculated by three methods depend on not only Mach number, but also strongly incidence. At great incidences, the differences are considerable even with small Mach number. At $\alpha=1^{\circ}$, differences of results calculated by compressible theory and by transonic theory are evident with $M_{\infty \text { dif }} \geq 0.77$; at $\alpha=3^{\circ}$ equivalently $M_{\infty \text { dif }} \geq 0.75$ and at $\alpha=5^{\circ}$ we 
have $M_{\infty}$ dif $\geq 0.72$. Since $M_{\infty}>M_{\infty}$ dif, if we consider flows are purely compressible, errors will become considerable. In the cases, it should use transonic methods.

To study effects of compressibility, which depend on both the Mach number, and the incidence, we use the code established by full potential equation method for calculating the variation of lift coefficients with the two parameters. Results are presented in Fig. 11. With $\alpha=1^{\circ}$ supersonic regions appear at Mach number $M_{\infty}$ alfal $=0.7$; with $\alpha=3^{\circ}$ supersonic regions appear at Mach number $M_{\infty}$ alfa3 $=0.6$; increasing angles of attack $\alpha=5^{\circ}$ and $\alpha=8^{\circ}$, equivalent free Mach numbers $M_{\infty \text { alfa } 5}=0.5$ and $M_{\infty \text { alfas }}=$ 0.4 . When angle of attack $\alpha=11^{\circ}$, supersonic regions appear at very small free Mach number $M_{\infty}$ alfa11 $=0.3$. We use to accept that with $M_{\infty}<0.4$, flows are considered incompressible. However, according to transonic theory, $\alpha=11^{\circ}$ is an angle of attack at which there is not yet the separation phenomena on upper of a Naca 0012, but with this angle of attack a supersonic region appears at a free Mach number 0.3 .

Our numerical essays show that only for free Mach number $M_{\infty}<0.25$, all over the profile do not appear any supersonic point.

Fig. 12 shows pressure distributions on a Naca 0012 profile with $\alpha=5^{\circ}$ and $M_{\infty}=0.65$ calculated by two methods: compressible theory method and transonic theory method. Results of lift coefficient calculated by the two methods are not very different $\left(C_{L}=0.74\right.$ and $C_{L}=0.77$ ). However, pressure distribution laws are very different in using the two methods. These laws show that the loading property on profile is very different for two results calculated from two theories: compressible theory and transonic theory.

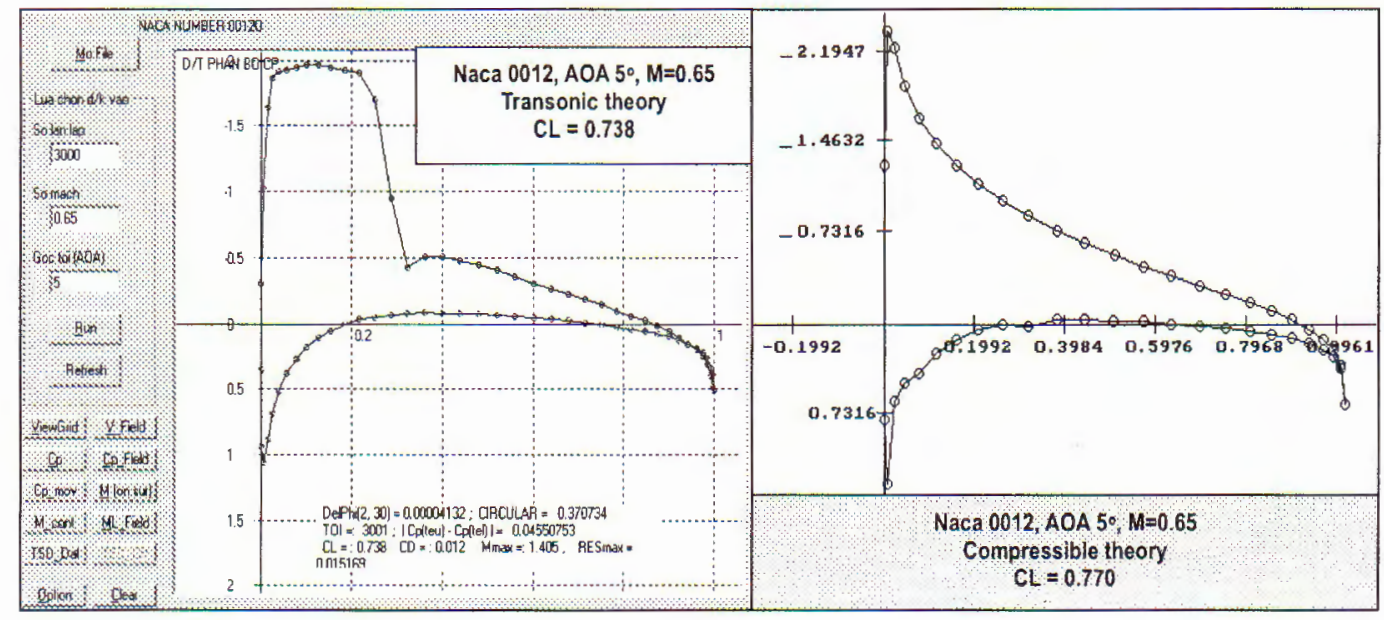

Fig. 12. Pressure coefficient distribution on Naca 0012, Alfa $5^{\circ}, \mathrm{M}=0.65$ Calculated by transonic theory and compressible theory

\section{DISCUSSION}

Numerical results calculated for subsonic flows by three methods: incompressible, compressible and transonic permit to reduce following comments:

For an aerodynamic profile, the local compressibility and the transonic effect depend on not only the free Mach number, but also the incidence. With great value of incidence 
(when boundary layers are not yet separated), a local supersonic region can appear at very small free Mach number, in the order of 0.3 .

For subsonic problems, if the incidence is great even when the free Mach number is moderate, because of local compressibility, it is necessary to treat the problems under transonic theory in order to consider the shock wave effect.

Note that the appearance of shock waves on airfoil changes a lot the loading property in comparison with using the hypothesis of flow without shock wave. It is effective ever when we obtain similar results of lift coefficient after integrating pressure distribution on airfoil.

The study is implemented with the party financial support from National Council of Natural Sciences.

\section{REFERENCES}

1. Hoang Thi Bich Ngoc, Vu Manh Cuong, Nguyen Manh Hung, Calculating aerodynamic forces on wing system of subsonic airplanes, Journal of Science 8 Technology, ISSN 0868-3980, No 48-49, 2004, pp 119-123.

2. Joseph katz Allen Plotkin, Low speed Aerodynamics, McGraw-Hill, USA, 1991.

3. John D. Anderson, Fundamentals of Aerodynamics, McGraw-Hill, Singapore, 2001.

4. D. Cole, L. Cook, Transonic Aerodynamics, Elsevier Science Ed, Netherlands 1991.

5. Hoang Thi Bich Ngoc, Le Hong Chuong, Numerical calculation of transonic flows by solving full potential equation, Proceeding of National Conferences on Engineering Mechanics, Hanoi, 10/2006, pp. 171-180.

6. J. F. Thompson, Numerical grid generation, Elsevier Science Publishing Co, USA, 1997.

7. W. Mason, Configuration Aerodynamics, Virginia Tech, USA, 2006.

Received January 16, 2007

\section{ÀNH HƯởNG CƯA TÍNH NÉN DƯợC TỚI CẢC DẶC TRƯNG KHÍ ĐỘNG CƯA PROFIL CÁNH XÉT THEO LÝ THUYẾT DÒNG QUÁ DỘ ÂM}

Dòng quá độ âm là một bài toán phức tạp. Ở một số Mach nhất định, trong chuyển động của chất khí tồn tại sự chuyển tiếp cục bộ từ dưới âm sang trên âm và ngược lại, đặc biệt là sự bất liên tục của dòng khi qua sóng va. Tính chất của chuyển động dưới âm và trên âm rất khác nhau, do vâyy, phương pháp tính toán cũng khác nhau dòng dưới âm có phương trình chuyển động dạng elip còn phương trình chuyển động của dòng trên âm có dạng hyperbol. Với các chương trình lập được (theo lý 'thuyết dòng không nén được, dòng nén được và dòng quá độ âm), chúng tôi đã thực hiện việc nghiên cứu các dặc trưng của dòng với sự thay đổi của tốc độ từ chế độ được xem là không nén được đến chế độ quá độ âm dưới âm. Các nghiên cứu cũng được tiến hành để xét ảnh hưởng của góc tới đến hiệu ứng quá độ ârn. Kết quà tính toán cho thấy, tính nén cục bộ của chất lỏng không chỉ phụ thuộc vào tốc độ chuyễn động mà còn phụ thuộc rất rỗ rệt vào góc tới. Ở một góc tới tương đối lớn, vùng trên âm cục bộ có thể xuất hiện ngay cả khi số Mach vô cùng $M \sim(0,3)$, là số Mach thông thường có thể coi là dòng không nén được. Những kết quả nghiên cứu này cho thấy ở chế độ làm việc nào tính nén cục bộ là đáng kể và cần thiết phài xét bài toán theo lý thuyết dòng quá độ âm.

E-mail: hoangthibichngoc@yahoo.com 